\title{
Cancer Clinical Trials Education Program
}

National Cancer Institute

\section{Source}

National Cancer Institute. Cancer Clinical Trials Education Program. NCI Thesaurus. Code C20086.

The Cancer Clinical Trials Education Program provides training to nurses and social workers to educate patients and their families about clinical trials. (Bypass Budget 2002) 